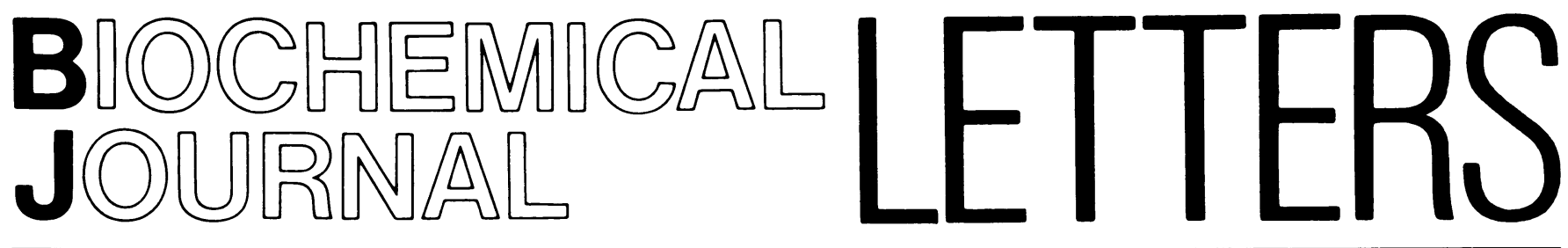

\section{The activity of mitochondrial water}

Recently it has been proposed that the activity of free water in the mitochondrial matrix (Srere, 1985) and the mitochondrial cristae (Candipan \& Sjostrand, 1984) can be very much less than that of cytosolic water. This is in contrast to the proposal of Garlid (1979) that the activity of free water in the mitochondrial matrix is the same as that of cytosolic water. Since water is a substrate or product in a large number of mitochondrial reactions, a significant decrease in the activity of water in the mitochondria, as proposed (Srere, 1985), would be expected to have a significant effect on the extent and direction of these reactions. The activity of the total pool of mitochondrial water could be less than that of the cytosolic pool of water due to the binding of water to mitochondrial proteins (see, e.g., Srore, 1985). However, the possibility that a pool of free water within certain areas of the mitochondria has a lower activity than that of the cytosol cannot be so unless the mitochondrial membrane possesses certain physical properties not previously observed or that the mitochondria could pump water to maintain a water activity gradient.

The properties that the mitochondrial membrane would have to possess to maintain a water activity gradient would be that the membrane is either impermeable to water or able to maintain a turgor pressure. The possibility that the mitochondrial membrane is impermeable to water is inconsistent with the well-established observations that mitochondria will readily shrink and swell under conditions where the osmolarity of the external media has been altered (Claude, 1946; Dianzani, 1953; Raaflaub, 1953; Tedeschi \& Harris, 1955) or the internal osmotic environment of the mitochondria has been changed by the energy-dependent movement of ions into or out of the mitochondria (Raaflaub, 1953; Harman \& Feigelson, 1952a,b; Lehninger \& Ray, 1957; Azzi \& Azzone, 1967; Izzard \& Tedeschi, 1970). The other possibility, that the mitochondrial membrane can maintain a turgor pressure, has been proposed (Bartley et al., 1969). This does not seem likely though when one considers the flexibility of the mitochondrial membrane observed during volume changes of the matrix (Tedeschi \& Harris, 1955; Hackenbrock, 1966; Stoner \& Sirak, 1969 ) and the fact that isolated mitochondria behave as osmometers when exposed to external media of varying osmotic strength (Tedeschi \& Harris, 1955; Bentzel \& Solomon, 1967; Garlid, 1979; Beavis et al., 1985). The observed differences between the total osmotically active material within the mitochondria and in the cytosol (Bartley et al., 1969) were most likely due to the binding of some of the solutes within the matrix of the mitochondria.

The alternative that the mitochondria could establish an activity gradient of water across the matrix membrane by pumping water has been considered previously (Bartley et al., 1969). The energy required to pump water out of the mitochondria was calculated to be $385 \mathrm{~J} / \mathrm{s}$ per $\mathrm{ml}$ of mitochondria (Bartley et al., 1969) for a water gradient of 1.00233 . This value is equivalent to $5.0 \mathrm{~kJ} / \mathrm{min}$ per $\mathrm{g}$ wet wt. of liver (assuming $330 \mathrm{mg}$ of mitochondrial protein $/ \mathrm{ml}$ of mitochondria and $70 \mathrm{mg}$ of mitochondria/ $\mathrm{g}$ wet wt. of liver) or $81 \mathrm{mmol}$ of ATP hydrolysed/min per $\mathrm{g}$ wet wt. of liver (assuming a cytosolic phosphorylation potential of $\left.1 \times 10^{5} \mathrm{M}^{-1}\right)$. Under optimal conditions the liver produces about $65 \mu \mathrm{mol}$ of $\mathrm{ATP} / \mathrm{min}$ per $\mathrm{g}$ wet wt. (Krebs et al., 1974); thus it can be seen that the energy required to maintain even a minimal concentration gradient of water across the mitochondrial membrane far exceeds the liver's energy production capabilities.

Further evidence for a pool of free water within the mitochondrial matrix is given by the observations of Williamson et al. (1967) on the reactions catalysed by the enzymes $\beta$-hydroxybutyrate dehydrogenase (EC 1.1.1.30) and glutamate dehydrogenase (EC 1.4.1.2). They observed that the enzymes shared a common pool of mitochondrial $\mathrm{NAD}^{+}$and NADH and that these reactions were in near equilibrium. In addition, the reaction catalysed by glutamate dehydrogenase:

$$
\begin{aligned}
& \text { L-glutamate }^{1-}+\mathrm{NAD}^{+}+\mathrm{H}_{2} \mathrm{O} \leftrightarrow \\
& \text { 2-oxoglutarate } \\
&
\end{aligned}
$$

has water as one of the reactants; therefore, any differences in the activity of water within the matrix of the mitochondria should be reflected in the mass action ratio of the metabolites of the glutamate dehydrogenasecatalysed reaction. Williamson et al. (1967) found no difference between the mass action ratios of the metabolites in vivo and the equilibrium constant determined in vitro. The simplest explanation of these observations is that the $\mathrm{NAD}^{+}$and NADH are free to diffuse in a pool of water accessible to both enzymes and that the activity of this pool of water is the same as a bulk water solution of ionic strength $0.25 \mathrm{M}$. Changes of water activity of less than $10 \%$ would not be detected by this method due to the uncertainty of the analytical data. However, a decrease in water activity of sufficient magnitude to affect reactions in which water is a product or reactant, as has been proposed (Srere, 1985) should be seen in the nearequilibrium position of the glutamate dehydrogenasecatalysed reaction.

While the analytical data for the near-equilibrium position of the glutamate dehydrogenase-catalysed reaction is not accurate enough on its own to say that the activity of water in the mitochondria is the same as in the cytosol, when these data are considered with the observations of the behaviour of mitochondria in media of various osmotic strengths, as cited above, this appears to be the case. Thus if there is a pool of free water within 
the mitochondria and water freely diffuses across the mitochondrial membrane then since, unlike plant cells and bacteria, mitochondria cannot maintain a turgor pressure, the osmotic activity within the mitochondria must be the same as in the cytosol. This is so since there is no way the mitochondria can prevent the movement of water across the membrane to equalize the activity of water. The movement of solutes into or out of the mitochondria will be followed by water movement in order to maintain osmotic equilibrium. This argument, coupled with the earlier observations that the activity of water in tissue was the same as in the extracellular fluid (Hill, 1930; Conway \& McCormack, 1953; Maffly \& Leaf, 1959), leads to the conclusion, in agreement with Garlid (1979), that there is a pool of water in all cellular compartments which has the same activity of water as the plasma - as long as the cellular compartment has a membrane which is permeable to water and which cannot maintain a turgor pressure.

While having established that a pool of water exists within the matrix of the mitochondria in which the activity of water is the same as in the cytosol and plasma, what is not known is the size of the pool of free water. The volume of the pool is almost certainly less than that of the total mitochondrial water, since the protein concentration within the matrix is about $40 \%(\mathrm{~g} / 100 \mathrm{ml}$, see, e.g., Srere, 1985). An approximation of the bound matrix water can be made from the determination of the osmotically inactive water in isolated mitochondria. This value has been reported to be between $30 \%$ and $50 \%$ of the total matrix water (Tedeschi \& Harris, 1955; Bentzel \& Solomon, 1967; Harris \& van Dam, 1968; Garlid, 1979; Beavis et al., 1985). How these values relate to the volume of free water within the matrix in vivo is unclear. It is however likely that the volume of free water in the matrix in vivo is only a fraction of the total matrix water content, as has been previously proposed (Srere, 1985). Thus it should be noted that the calculation of the mitochondrial concentration of various metabolites and ions based on the measurement of their total mitochondrial content is fraught with difficulty due to the uncertainty of the volume of free water within the mitochondria.

\section{William L. GITOMER}

Laboratory of Metabolism and Molecular Biology, NIAAA, 12501 Washington Avenue, Rockville, MD 20852, U.S.A.

Azzi, A. \& Azzone, G. F. (1967) Biochim. Biophys. Acta 135, $444-453$

Bartley, W., Dean, B. \& Ferdinand, W. (1969) J. Theor. Biol. 24, 192-202

Bentzel, C. J. \& Solomon, A. K. (1967) J. Gen. Physiol. 50, $1547-1563$

Beavis, A. D., Brannan, R. D. \& Garlid, K. D. (1985) J. Biol. Chem. 260, 13424-13433

Candipan, R. C. \& Sjostrand, F. S. (1984) J. Ultrastruct. Res. 89, $249-260$

Claude, A. (1946) J. Exp. Med. 84, 61-89

Conway, E. J. \& McCormack, J. I. (1953) J. Physiol. (London) 120, $1-14$

Dianzani, M. U. (1953) Biochim. Biophys. Acta 11, 353-367

Garlid, K. D. (1979) in Cell-Associated Water (Drost-Hansen, W. \& Clegg, J., eds.), pp. 293-361, Academic Press, New York

Hackenbrock, C. R. (1966) J. Cell Biol. 30, 269-297

Harman, J. W. \& Feigelson (1952a) Exp. Cell Res. 3, 47-58

Harman, J. W. \& Feigelson (1952b) Exp. Cell Res. 3, 509-525

Harris, E. J. \& van Dam, K. (1968) Biochem. J. 106, 759-766

Hill, A. V. (1930) Proc. R. Soc. London Ser. B 106, 477-505

Izzard, S. \& Tedeschi, H. (1970) Proc. Natl. Acad. Sci. U.S.A. 67, 702-709

Krebs, H. A., Cornell, N. W., Lund, P. \& Hems, R. (1974) in Regulation of Hepatic Metabolism (Lundquist, F. \& Tygstrup, N., eds.), pp. 549-567, Academic Press, New York Lehninger, A. L. \& Ray, B. L. (1957) Biochim. Biophys. Acta 26, 643-644

Maffly, R. H. \& Leaf, A. (1959) J. Gen. Physiol. 42, 1257-1275

Raaflaub, J. (1953) Helv. Physiol. Pharmacol. Acta 11, 142-156

Srere, P. A. (1985) in Organized Multienzyme Systems: Catalytic Properties (Welch, G. R., ed.), pp. 1-61, Academic Press, New York

Stoner, C. D. \& Sirak, H. D. (1969) J. Cell Biol. 43, 521-538

Tedeschi, H. \& Harris, D. L. (1955) Arch. Biochem. Biophys. 58, 52-67

Williamson, D. H., Lund, P. \& Krebs, H. A. (1967) Biochem. J. 103, 514-527

Received 5 April 1987 